\title{
Increased glycolipid storage produced by the inheritance of a complex intronic haplotype in the a-galactosidase A (GLA) gene
}

Javier Gervas-Arruga 1,2,3,4* Jorge J. Cebolla ${ }^{2,3,4}$, Pilar Irun 1,2,3,4, Javier Perez-Lopez ${ }^{5}$, Luis Plaza ${ }^{6}$, Jose C. Roche ${ }^{7}$, Jose L. Capablo ${ }^{7}$, Jose C. Rodriguez-Rey ${ }^{5}$, Miguel Pocovi ${ }^{3,4}$ and Pilar Giraldo ${ }^{1,2,3}$

\begin{abstract}
Background: Accumulation of galactosphingolipids is a general characteristic of Fabry disease, a lysosomal storage disorder caused by the deficient activity of a-galactosidase A encoded by the GLA gene. Although many polymorphic GLA haplotypes have been described, it is still unclear whether some of these variants are causative of disease symptoms. We report the study of an inheritance of a complex intronic haplotype $(\mathrm{ClH})(\mathrm{C} .-10 \mathrm{C}>\mathrm{T}, \mathrm{c} .369+990 \mathrm{C}>\mathrm{A}$, c.370-81_370-77delCAGCC, c.640-16A > G, c.1000-22C > T) within the GLA gene associated with Fabry-like symptoms and galactosphingolipid accumulation.

We analysed a-Gal A activity in plasma, leukocytes and skin fibroblasts in patients, and measured accumulation of galactosphingolipids by enzymatic methods and immunofluorescence techniques. Additionally, we evaluated GLA expression using quantitative PCR, EMSA, and CDNA cloning.
\end{abstract}

Results: $\mathrm{ClH}$ carriers had an altered GLA expression pattern, although most of the carriers had high residual enzyme activity in plasma, leukocytes and in skin fibroblasts. Nonetheless, $\mathrm{ClH}$ carriers had significant galactosphingolipid accumulation in fibroblasts in comparison with controls, and also glycolipid deposits in renal tubules and glomeruli. EMSA assays indicated that the c.-10C > T variant in the promoter affected a nuclear protein binding site.

Conclusions: Thus, inheritance of the $\mathrm{CIH}$ caused an mRNA deregulation altering the GLA expression pattern, producing a tissue glycolipid storage.

Keywords: GLA, Fabry disease, Haplotypes, Galactosphingolipids, a-galactosidase A

\section{Background}

$\alpha$-galactosidase A ( $\alpha$-Gal A, EC3.2.1.22) is a lysosomal enzyme that hydrolyses the terminal $\alpha$-galactosyl moieties from glycolipids. $\alpha-G a l$ A is encoded by the GLA gene and mutations in this gene causes deficiency or absence of the enzyme, resulting in Fabry disease (FD) (OMIM 301500), an X-linked inherited lysosomal storage disorder. This disease leads to accumulation of globotriaosylcermide $\left(\mathrm{Gb}_{3}\right)$, globotriaosylsphingosine (lyso- $\mathrm{Gb}_{3}$ ), galabiosylceramide

\footnotetext{
*Correspondence: gervas.j@gmail.com

${ }^{1}$ Centro de Investigación Biomédica en Red de Enfermedades Raras (CIBERER), Zaragoza, Spain

${ }^{2}$ Translational Research Unit, Instituto de Investigación Sanitaria Aragón (IIS

Aragón), Miguel Servet University Hospital, Zaragoza, Spain

Full list of author information is available at the end of the article
}

$\left(\mathrm{Ga}_{2}\right)$ and neutral glycosphingolipids in lysosomes of several tissues, mainly in the endothelium of the vascular tree [1]. Depending on the GLA mutation and when manifestations initially occur, FD is classified as late-onset or classic phenotype. In males with no, or reduced, $\alpha$-Gal A enzyme activity, clinical manifestations of the classic form include acroparesthesias, angiokeratomas, hypohidrosis, corneal and lenticular opacities, cardiac dysfunction and brain and renal involvement with proteinuria [2]. Heterozygous females can either be asymptomatic, due to random X-chromosomal inactivation [3], or can develop the classic phenotype [1]. Because of the nonspecific nature of its clinical manifestations, FD often remains 
undiagnosed in concordance with the prevalence calculated in some studies $[4,5]$; however, early treatment is essential to avoid significant disease progression [6, 7].

Over 700 GLA mutations, including missense and nonsense mutations, rearrangements, and splicing defects, have been identified as causing FD [8] (http://www.hgmd.cf. ac.uk/ac/index.php). GLA [ENSG:00000102393] has seven splice variants (http://www.ensembl.org) and aberrant splicing accounts for $\sim 5 \%$ of mutations in FD (reported to the Human Gene Mutation Database; http://www.hgmd.cf. ac.uk), but information on pre-mRNA splicing is only available for a limited number of patients. Exonic mutations may also alter splicing, but are not easily recognized [9]. Many polymorphic GLA variants have been described, but it is unclear if haplotypes formed by combinations of these variants correlate with FD. A complex intronic haplotype $(\mathrm{CIH})$ within the GLA gene (c.-10C $>\mathrm{T}$, c.640-16A $>\mathrm{G}$, c.1000-22C $>$ T) is associated with early occurrence of small-fibre neuropathy [10]. A screening study found a second CIH (c.-10C > T, c.370-81_370-77delCAGCC, c.640-16A > G, c. $1000-22 \mathrm{C}>\mathrm{T}$ ) in $8.9 \%$ of subjects with FD symptoms [11]; associated with hypertrophic heart disease [12] and, additionally, an analysis of the male control population of a suspected FD female index case permitted the identification of seven different GLA haplotypes [13]. Finally, a recent study described a large family with four male/female carriers of a $\mathrm{CIH}$ who developed a classical phenotype with a mild renal and neurological involvement [14]. Some of these intronic variants have been reported as polymorphic variants in general population [15-17].

We performed a functional characterization of a large family with a $\mathrm{CIH}$ in the GLA gene and investigated the molecular pathological mechanisms associated with different FD-related clinical manifestations. We demonstrate that the inheritance of this $\mathrm{CIH}$ causes GLA gene deregulation and glycolipid storage.

\section{Methods}

\section{Patients}

We studied a family with different FD-related clinical manifestations. This family carried a $\mathrm{CIH}$ (c.-10C $>\mathrm{T}$ [rs2071225], c.369+990C>A [rs1023431], c.370-81_37077delCAGCC [rs5903184], c.640-16A > G [rs2071397], c.1000-22C > T [rs2071228]). The family consisted of 15 individuals (6 heterozygous and 4 hemizygous for $\mathrm{CIH}$ ) aged between 7 and 72 years. Written informed consent was obtained from all patients including those from the parents on the behalf of the minors involved in our study. The study was approved by the Ethics Committee of Aragon (CEICA) and was conducted in accordance with the Declaration of Helsinki of 1975, as revised in 2008 .

\section{Reagents}

The recombinant enzyme used was agalsidase alfa (REPLAGAL) from Shire pharmaceuticals. As a source of enzyme, we used the residual amounts of the reconstituted recombinant enzyme prepared for the treatment of FD patients. TNF $\alpha$ was purchased from Miltenyi Biotec. The pharmacological chaperone, DGJ (1deoxygalactonojirimycin hydrochloride), was purchased from Santa Cruz Biotechnology. The anti-human CD77 $\left(\mathrm{Gb}_{3}\right)$ primary rat monoclonal antibody used for immunofluorescence analysis was purchased from Biorbyt; the anti-human CD17 (lactosylceramide) mouse monoclonal antibody was from Santa Cruz Biotechnology and the anti-human LAMP1 rabbit monoclonal antibody was from Sigma-Aldrich. Secondary conjugated antibodies were Alexa Fluor 546 goat anti-rabbit IgG, Alexa Fluor 488 goat anti-rat IgG and Alexa Fluor 488 goat antimouse IgG, all from Life Technologies.

\section{a-Gal A activity assay}

The activity of $\alpha$-Gal A was determined in plasma, lysed leukocytes and lysed fibroblasts (in triplicate) with a fluorometric assay using the artificial substrate 4-methylumbelliferyl (MU)- $\alpha$-D-galactopyranoside (SigmaAldrich); for the assay of cell extracts, N-acetyl-Dgalactosamine (Sigma-Aldrich) was used to inhibit $\alpha$-galactosidase B ( $\alpha$-Gal B) [18]. The fluorescence of released 4-MU was measured in two replicates at an excitation wavelength of $366 \mathrm{~nm}$ and emission wavelength of $445 \mathrm{~nm}$ in a fluorometer (Perkin Elmer LS-45).

\section{Fibroblast culture}

Human skin fibroblasts were cultured in $175 \mathrm{~cm}^{2}$ flasks in Dulbecco's modified Eagle's medium (DMEM) supplemented with GlutaMAX, $10 \%$ heat-inactivated fetal bovine serum (FBS), $0.5 \% \beta$-amphotericin $(250 \mu \mathrm{g} / \mathrm{mL})$ and the antibiotics streptomycin $(100 \mathrm{mg} / \mathrm{L})$ and penicillin $(100 \mathrm{U} / \mathrm{L})$. Cells were maintained at $37{ }^{\circ} \mathrm{C}$ in a $5 \%$ $\mathrm{CO}_{2}$ atmosphere and the medium was replenished every 72 h. After reaching confluence, cells were kept quiescent for 5 days, washed with PBS and harvested by trypsin $(0.05 \%$ trypsin/EDTA for $5 \mathrm{~min})$. All reagents were provided by Gibco-Invitrogen. Cell suspensions were pelleted by centrifugation at $290 \times \mathrm{g}$ for 5 min. After removing the supernatant, cells were washed twice with PBS and stored at $-20{ }^{\circ} \mathrm{C}$ for further analysis.

\section{Cell culture model of lysosomal storage dysregulation}

Fibroblasts were cultured in DMEM with $1 \%$ inactivated FBS in 6-well culture plates $\left(160,000\right.$ cells $\left./ 9.5 \mathrm{~cm}^{2}\right)$. Twenty-four hours before experimentation, cells were activated with $0.1 \mathrm{nM} \mathrm{TNF} \alpha$ for $16 \mathrm{~h}$. After activation, the medium was renewed and, where indicated, cells were 
additionally incubated with DGJ $(500 \mu \mathrm{M})$ for $24 \mathrm{~h}$ to inhibit endogenous $\alpha$-galactosidase activity [19] or with agalsidase alfa, by adding $3 \mathrm{ml}$ of the enzyme solution $(1.32 \mu \mathrm{g}$ of enzyme per ml; final activity $3.8 \mu \mathrm{mol} \mathrm{MU}$ $\mathrm{mg}^{-1} \cdot \mathrm{h}^{-1}$ ) [20], to analyze galactolipid degradation as an endogenous control. Cell cultures were incubated for different periods of time $(0,16$ and $24 \mathrm{~h})$ and at least two $9.5 \mathrm{~cm}^{2}$ wells were analyzed for each treatment combination.

\section{Quantification of galactosphingolipids}

Determination of galactosphingolipids using galactose oxidase was carried out in cell pellets from lysed leukocytes and fibroblasts previously suspended in $1 \%$ sodium taurocholate (Sigma-Aldrich) and disrupted by combination of ultrasound short pulse (VibraCell) and timing-out on ice. Samples were kept on ice during the procedure. The lysate was centrifuged at $112 \times \mathrm{g}$ for $10 \mathrm{~min}$ at $4{ }^{\circ} \mathrm{C}$ to eliminate cell debris and $50 \mu \mathrm{l}$ of supernatant was used for quantification. Measurement of galactosphingolipids was performed using the Amplex Red Galactose/Galactose Oxidase Assay Kit (Invitrogen).

\section{Immunofluorescence analysis}

Immunocytochemistry was performed to examine the distribution of CD77, CD17 and LAMP1. Fibroblasts grown on coverslips were fixed with $4 \%$ paraformaldehyde for CD77/LAMP1 analysis and with methanol for CD17/LAMP1 localization, permeabilized with $0.1 \%$ saponin and blocked with $0.1 \%$ saponin $5 \%$ BSA diluted in PBS. Cells were incubated with primary antibodies (CD77 diluted to $50 \mu \mathrm{g} / \mathrm{ml}, \mathrm{CD} 17$ diluted to $2 \mu \mathrm{g} / \mathrm{ml}$ and LAMP1 diluted to $0.2 \mu \mathrm{g} / \mathrm{ml}$ ) overnight at $4{ }^{\circ} \mathrm{C}$ and then conjugated secondary antibodies diluted to $0.1 \mu \mathrm{g} / \mathrm{ml}$ were added and were incubated for $20 \mathrm{~min}$ at $25{ }^{\circ} \mathrm{C}$. Coverslips were mounted on slides and covered with $5 \mu \mathrm{l}$ of DAPI-Mowiol medium (Life Technologies/ Calbiochem). All samples were examined with an Olympus FluoView FV10i confocal microscope under identical conditions. We used $405 \mathrm{~nm}, 473 \mathrm{~nm}$ and $635 \mathrm{~nm}$ excitation lasers, which were switched on separately to reduce crosstalk of the two fluorochromes. A threshold was applied to the images to exclude 99\% of the signal found in control images. Pixel and cell surface fluorescence quantification was done using FV10-ASW 3.1 software from Olympus.

\section{Molecular GLA analysis}

Genomic DNA was isolated from whole blood by standard procedures. The entire GLA gene (g.101409127g.101397726) including promoter, exons and introns, was amplified by PCR using the primers described in Additional file 1. Amplicons were purified and sequenced in an automated DNA sequencer (3500XL genetic analyser, Applied Byosistems). Sequences were compared with the genomic GLA reference sequence [ENSG:00000102393].

Multiplex Ligand Probe Amplification (MLPA) GLA analysis Patients F1.1, F1.4 and F1.10 were analysed by MLPA technique in order to find any pathological rearrangement in GLA gene. The details of the MLPA probe target regions and test methodology are described by MRC Holland (http://www.mlpa.com). SALSA MLPA P159 GLA probemix, version A2 (MRC Holland, Netherlands) was used and data were normalized using 3 healthy controls matched by age and sex.

\section{RNA isolation, CDNA synthesis, small RNA cloning, and quantitative real-time PCR}

Total RNA was isolated from patients and control peripheral blood samples using the PAXgene Blood RNA Kit (PreAnalytiX). RNA integrity was assessed by agarose gel electrophoresis and concentration was determined in a NanoVue 4282 V1.7.3 Spectrophotometer (GE Healthcare). Total RNA (1 $\mu \mathrm{g})$ was reverse transcribed in triplicate $20 \mu \mathrm{L}$ reactions using the SuperScript II reverse transcriptase Kit (200 units) and Oligo $(\mathrm{dT})_{12-18}(500 \mu \mathrm{g} / \mathrm{mL})$ (Invitrogen). The RTPCR profile was: $10 \mathrm{~min}$ at $42{ }^{\circ} \mathrm{C}, 45 \mathrm{~min}$ at $60{ }^{\circ} \mathrm{C}$, and $5 \mathrm{~min}$ at $95{ }^{\circ} \mathrm{C}$.

To identify splicing variants, the entire GLA mRNA was amplified by PCR using $1 \mu \mathrm{L}$ cDNA and the primers described in Additional file 1. The amplification conditions were: $2 \mathrm{~min}$ at $94{ }^{\circ} \mathrm{C}$ followed by 40 cycles of $20 \mathrm{~s}$ at $94{ }^{\circ} \mathrm{C}, 30 \mathrm{~s}$ at $57^{\circ} \mathrm{C}$, and $30 \mathrm{~s}$ at $72{ }^{\circ} \mathrm{C}$, and a final extension of $72{ }^{\circ} \mathrm{C}$ for $4 \mathrm{~min}$. Amplicons were diluted and nested PCR was performed to amplify the GLA mRNA in two parts. Both amplicons were purified with ExoSap-IT (GE Healthcare) and sequenced.

A fragment of the 3' region of intron 6 (g.101398149g.101398099) was amplified from cDNA of CIH carriers by nested PCR using miScript PCR system and miScript Primer Assays (Qiagen) trying to identify small RNA fragments. The product was cloned into the pGEM-T Easy Vector (Promega) and purified with the PureLink Quick Plasmid Miniprep Kit (Invitrogen). Inserts were amplified by PCR with T7 and SP6 universal primers, and products were sequenced in forward and reverse directions.

Quantification of GLA mRNA was performed in triplicate samples from each patient using a quantitative real-time PCR (qPCR) method based on TaqMan technology (Applied Biosystems). Probe and primers for wild-type GLA (ENST00000218516) and GLA-M (cloned fragment) are listed in Additional file 1. qPCR 
was performed with the ABI Prism 7000 Sequence Detector (PE Applied Biosystems) using $20 \mathrm{ng}$ of cDNA in a reaction mixture containing $10 \mu \mathrm{l}$ Universal Master Mix without amperase, $300 \mathrm{nmol}$ of each primer and $200 \mathrm{nmol}$ of probe (Additional file 1). Conditions for qPCR were: $95{ }^{\circ} \mathrm{C}$ for 10 min followed by 40 cycles of $95{ }^{\circ} \mathrm{C}$ for $15 \mathrm{~s}$ and $60{ }^{\circ} \mathrm{C}$ for $1 \mathrm{~min}$. We used efficiency-corrected gene expression measurements [21].

\section{Electrophoretic mobility shift assay (EMSA)}

IRDye680-labelled double-stranded oligonucleotides with the sequence GCTGTCCGGT[C/T]ACCGTGACAA were purchased from LICOR Biosciences (Lincoln, NE, USA). The preparation of nuclear extracts and the electrophoresis procedures have been described previously [22]. EMSA results were analysed and quantified using the Odyssey Infrared Imaging System (LICOR Biosciences). For competition assays, an excess of unlabelled T-allele oligonucleotide was added to the mix prior to the addition of the labelled oligonucleotides. The inverse of band intensity was plotted against the excess of unlabelled oligonucleotide and the slope of the resulting straight line indicated the affinity of each allele for the proteins in the nuclear extract.

\section{Splice-site score (SSS)}

Splice mutations were analysed using the SSPNN program (http://www.fruitfly.org/seq_tools/splice.html) and a splice-site score (SSS) was obtained.

\section{Statistical analysis}

Statistical analysis was carried out using the SPSS software package (IBM). Normality of the distribution of variables was analysed by the Kolmogorov-Smirnov test, and mean comparison by the parametric $t$-test and one way ANOVA. Differences with $p \leq 0.05$ were considered statistically significant.

\section{Results \\ Patients}

The family pedigree is shown in Fig. 1. The index case (F1.1) was a 43-year-old female, with clinical records of acroparesthesias from adolescence, hypohidrosis, and reiterated episodes of abdominal pain with alternating phases of diarrhoea with constipation. At 40 years of age was referring several episodes of pain chest that requiring emergency care. At 41 years of age she was hospitalized by a new episode of chest pain and was diagnosed with anteroseptal myocardial infarction, requiring the implantation of three stents. The evaluation of hearth function by MRI showed residual fibrous scar by myocardial infarction in the territory of the anterior and apex segments. LV slightly dilated with decreased LVEF (48.4 \%) and generalized hypokinesia. Valvular function with MI moderate to severe and moderate AI. The cardiologic diagnosis suspicion was valvular and ischemic hearth variant secondary to Fabry disease. Complete haematological, neurological, and ophthalmological examinations were performed, and renal function was measured and determined to be normal. It discard associate factors of hypercoagulability status. Peripheral nervous conduction was evaluated by quantitative sensory test (QST) [23], which revealed abnormalities in the small fiber conduction compared with normal population. Physical examination indicated that the patient had absence of hemangiokeratomas, nodes or visceral enlargement, and no cardiovascular risks such as high plasmatic cholesterol, low c-HDL levels

CIH Hemizygous

CIH Heterozygous

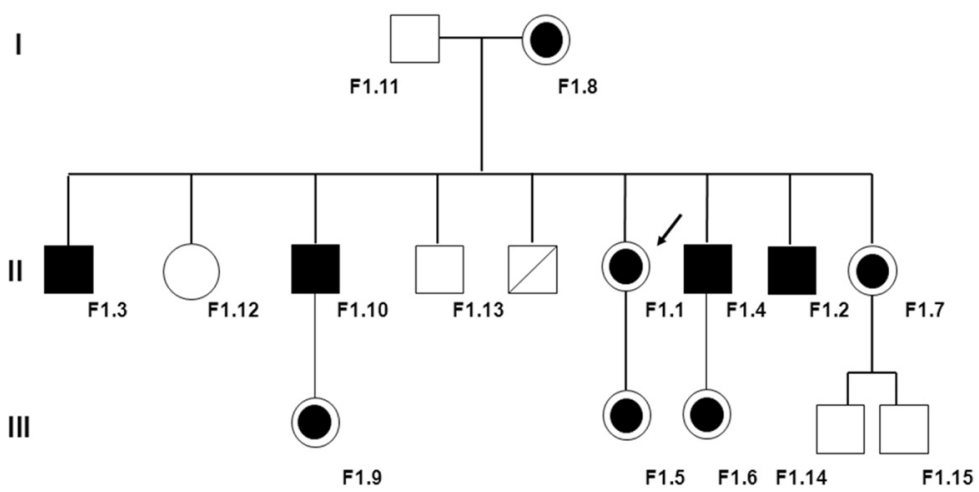

Fig. 1 Pedigree of the family and complex intronic haplotype (C.-10C > T, c.369+990C > A, c.370-81_370-77delCAGCC, c.640-16A > G, C.1000-22C > T) carriers. Index case is indicated with an arrow 
or hypertension. Genetic analysis revealed a $\mathrm{CIH}$ in the GLA gene: IVSO-10C $>\mathrm{T}(\mathrm{c} .-10 \mathrm{C}>\mathrm{T})$ within the promoter region, intron 2 IVS $2+990 \mathrm{C}>\mathrm{A}(\mathrm{c} .369+990 \mathrm{C}>$ A); IVS2-76_80del 5 (c.370-77_81 del CAGCC), intron 4 IVS4-16A > G (c.640-16A > G) and intron 6 IVS6-22C > T (c.1000-22C $>\mathrm{T}$ ). The same haplotype was identified in the patient's mother (F1.8) and daughter (F1.5), in four of her brothers (F1.2, F1.3, F1.4, and F1.10) and one of her two sisters (F1.7), as well as in the daughters (F1.6, F1.9) of two of the affected brothers. MLPA assays did not reveal any copy number differences in patients F1.1, F1.4 and F1.10.

At age 52 years, the first brother (F1.3) was referred for examination to exclude malignant monoclonal gammopathy IgG-kappa. At age 40 years, he underwent vertebral fixation surgery because of severe back pain. He reported acroparesthesia, heat intolerance, and hypohidrosis since childhood, as well as shortness of breath and inability to perform any physical activity. This patient was hemizygous for the $\mathrm{CIH}$.

The second brother (F1.10), hemizygous for the $\mathrm{CIH}$, was 49 years old. His main symptoms were related to left ventricular hypertrophy and valvular aortic stenosis associated with severe acral pain that demanded continuous intake of analgesic drugs.

The third brother (F1.13) did not accept to be a part of the study and the fourth brother was deceased.

The fifth brother (F1.4) was referred for hearing loss and mild acroparesthesia at 41 years of age. Renal involvement was characterised by microalbuminuria (34 $\mathrm{mg} / 24 \mathrm{~h}$ ) and glycolipid deposits in renal tubules and glomeruli (Fig. 2). It is important to note that this patient did not use chloroquine or amiodarone-like drugs. His 7-year-old daughter (F1.6) had microalbuminuria (29 mg/24 h), and was heterozygous for the $\mathrm{CIH}$.

The sixth brother (F1.2) was 39 years old, hemizygous for the $\mathrm{CIH}$, and was referred for acroparesthesias, bilateral hearing loss, heat intolerance and hypohidrosis, but no cardiac abnormalities were observed.

One sister (F1.7) was 37 years old and a carrier of the $\mathrm{CIH}$. She had a previous history of tachyarrhythmias, and since childhood she had acroparesthesias, hypohidrosis and heat intolerance. Her mother (F1.8) presented no clinical manifestations.

\section{a-Gal A activity in plasma, leukocytes and fibroblasts}

Enzymatic activity was measured in plasma, lysed leukocytes and fibroblasts from $\mathrm{CIH}$ carriers and normal healthy controls. The individual values from leukocytes and plasma are presented in Table 1 . The mean value of lysed leukocyte activity in the control group $(n=27)$ was $($ mean $\pm \mathrm{SD}) \quad 58.1 \pm 26.6 \mathrm{nmol} / \mathrm{mg}$ protein $/ \mathrm{h}$. Significantly lower levels were found in the $\mathrm{CIH}$ group $(n=8)$, $46.25 \pm 9.66 \mathrm{nmol} / \mathrm{mg}$ protein/h (Fig. 3a; $p \leq 0.05$ ). The mean value of plasma activity in the control group $(n=33)$ was (mean $\pm \mathrm{SD}) 20.8 \pm 12.5 \mathrm{nmol} / \mathrm{mL} / \mathrm{h}$, whereas the mean value for the $\mathrm{CIH}$ group $(n=9)$ was $19.5 \pm 10.3 \mathrm{nmol} / \mathrm{mL} / \mathrm{h}$. There was no significant difference between the plasma activity in control and $\mathrm{CIH}$ group (Fig. 3a). Enzymatic activity was also measured in cultured skin fibroblasts from controls and from patients F1.1, F1.3, F1.4 and F1.10. The activity measurements in the patients' fibroblasts were not significantly different to controls, although there was a trend for reduction in patient F1.10 and fibroblasts from patient F1.3 had significantly higher levels of $\alpha$-Gal A (Fig. 3b).

\section{In vitro model of lysosomal storage disease}

In order to accurately determine galactosphingolipid levels, we first used wild-type fibroblasts to establish a model of lysosomal storage dysregulation. Fibroblasts were treated or not with TNFa $(16 \mathrm{~h})$ to activate a proinflammatory response, followed by a medium change without TNF $\alpha$, and culturing was then continued

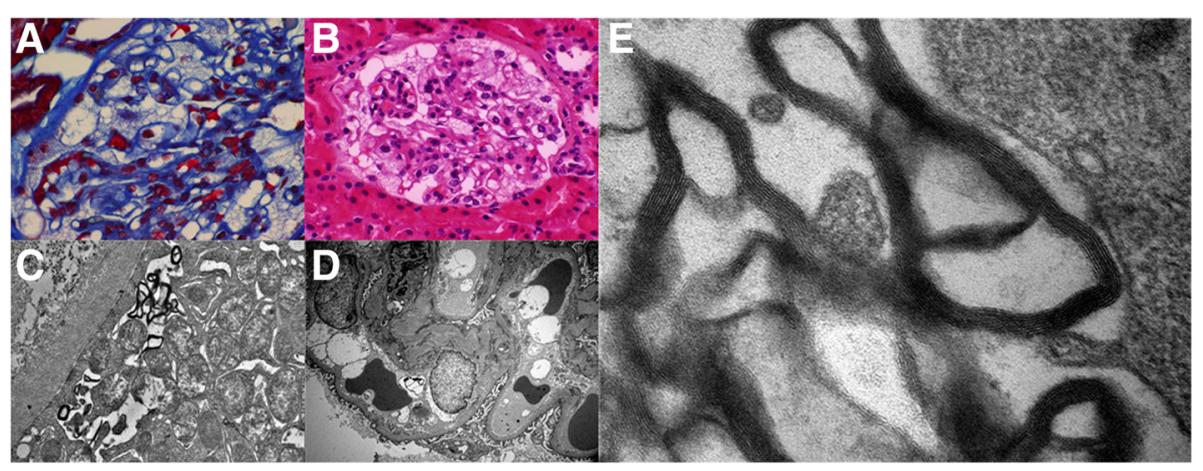

Fig. 2 Cytoplasmic vacuolation observed in a podocyte by light microscopy with a Masson's trichrome and $\mathbf{b}$ Haematoxylin and eosin staining. c Myelin-like structures in a podocyte, with concentric lamellated ultra-structural appearance. (Electron Microscopy). d Focal areas of podocyte effacement; amorphous myelin-like structures are visible in glomerular parietal epithelial cells and in endothelial cells (Electron Microscopy). e Myelin-like structures parallel with zebra-like body appearance (Electron Microscopy) 
Table 1 Clinical manifestations; a-Gal A activity in plasma and leukocytes, galactosphignolipid concentrations and GLA mRNA expression

\begin{tabular}{|c|c|c|c|c|c|c|c|c|c|c|}
\hline ID & SEX & Age & $\begin{array}{l}\text { Variants } \\
\mathrm{ClH}\end{array}$ & Clinical Manifestations & $\begin{array}{l}\text { galactosphingolipids } \\
\text { Leukocytes } \\
\text { (nmol/mg protein) }\end{array}$ & $\begin{array}{l}\text { galactosphingolipids } \\
\text { Fibroblasts } \\
\text { (nmol/mg protein) }\end{array}$ & $\begin{array}{l}\text { a-Gal A } \\
\text { Leukocytes } \\
\text { (nmol/mg protein/h) }\end{array}$ & $\begin{array}{l}\text { a-Gal A } \\
\text { Plasma } \\
(\mathrm{nmol} / \mathrm{mL} / \mathrm{h})\end{array}$ & $\begin{array}{l}\text { mRNA } \\
\text { GLA } \\
\text { RQ }\end{array}$ & $\begin{array}{l}\text { mRNA } \\
\text { GLA-M } \\
\text { RQ }\end{array}$ \\
\hline F1.1 & $f$ & 43 & Het & $\begin{array}{l}\text { Ischemic heart disease, Gastro- intestinal, } \\
\text { Fine fiber alterations }\end{array}$ & 0.62 & 0.83 & 63 & 23 & $0.48^{*}$ & 0.85 \\
\hline$F 1.2$ & $\mathrm{~m}$ & 39 & Hemi & $\begin{array}{l}\text { Acroparesthesias, Heat intolerance, } \\
\text { Hypohidrosis, Hearing loss }\end{array}$ & 0.13 & N/A & 57 & 19 & 0.41 & 5.47 \\
\hline F1.3 & $\mathrm{m}$ & 53 & Hemi & $\begin{array}{l}\text { Acroparesthesias, Heat intolerance, } \\
\text { Hypohidrosis }\end{array}$ & 0.11 & 0.80 & 38 & 14 & $0.36^{*}$ & 0.84 \\
\hline F1.4 & $\mathrm{m}$ & 41 & Hemi & $\begin{array}{l}\text { Hearing loss, Microalbuminuria, } \\
\text { Renal deposits }\end{array}$ & 0.11 & 1.12 & 37 & 15 & 0.88 & 2.56 \\
\hline F1.5 & $f$ & 20 & Het & N/A & 0.13 & N/A & 42 & 37 & N/A & N/A \\
\hline F1.6 & $f$ & 7 & Het & Microalbuminuria & N/A & N/A & N/A & 9 & N/A & N/A \\
\hline $\mathrm{F} 1.7$ & $f$ & 37 & Het & $\begin{array}{l}\text { Acropaesthesias, Microalbumminuria, } \\
\text { Hypohidrosis, Tachyarrhythmias }\end{array}$ & 0.06 & N/A & 43 & 15 & 1.06 & 1.51 \\
\hline $\mathrm{F} 1.8$ & $f$ & 72 & Het & N/A & 0.27 & N/A & 51 & 35 & 1.12 & 0.90 \\
\hline$F 1.10$ & $\mathrm{~m}$ & 49 & Hemi & Left Ventricular Hypertrophy & 1.93 & 0.93 & 39 & 9 & $0.02^{* *}$ & $117.76^{* *}$ \\
\hline
\end{tabular}

$\mathrm{CIH}=$ c.-10C > T [rs2071225], c.369 + 990C > A [rs1023431], c.370-81_370-77delCAGCC [rs5903184], c.640-16A > G [rs2071397], c.1000-22C > T [rs2071228]. The mean \pm SD normal concentration of leukocytes galactosphingolipids is $(n=17) 0.33 \pm 0.3(\mathrm{nmol} / \mathrm{mg}$ protein). The mean \pm SD normal concentration of fibroblasts galactosphingolipids is $(n=5) 0.63 \pm 0.12$ (nmol/mg protein). The normal mean \pm SD of a-Gal A leukocyte activity in our assay is $(n=27) 58.1 \pm 26.6\left(\mathrm{nmol} / \mathrm{mg}\right.$ protein/hour) and normal mean \pm SD of $a$-Gal A plasma activity is $(n=33) 20.8 \pm 22.03(\mathrm{nmol} / \mathrm{mL} / \mathrm{hour}){ }^{*}=p<0.05{ }^{* *}=p<0.001 . \mathrm{N} / \mathrm{A}=\mathrm{Not}$ applicable 

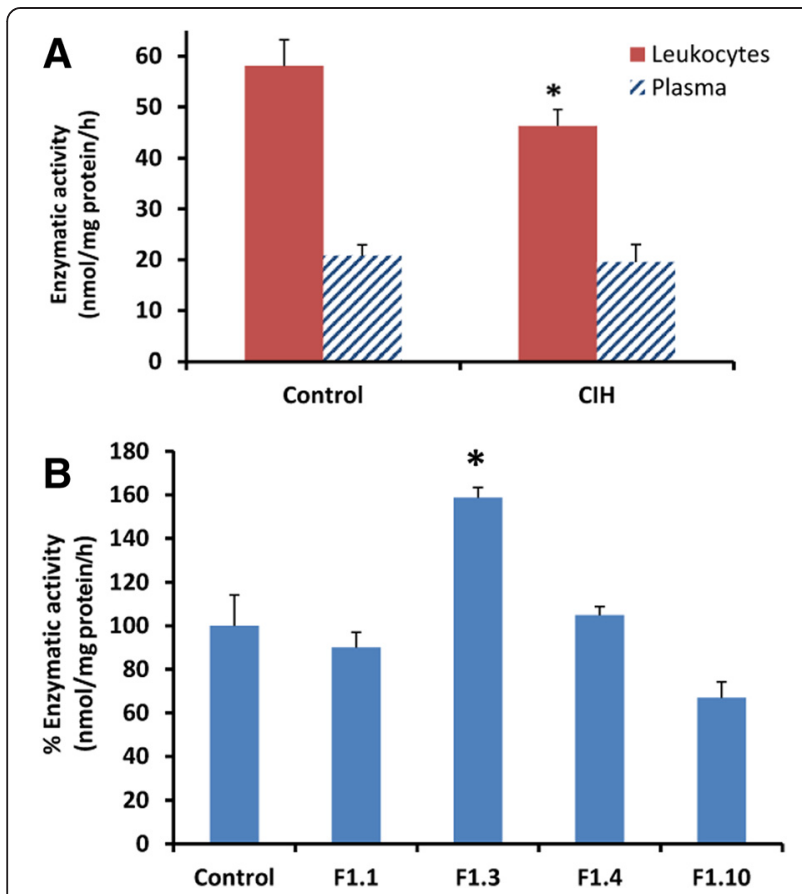

Fig. $\mathbf{3}$ a-Gal enzyme activity. a Enzymatic activity in lysed leukocytes (nmol/mg protein/hour) and plasma (nmol/mL/hour), represented as mean \pm SEM. $\mathbf{b}$ Enzymatic activity in lysed fibroblasts $(\mathrm{nmol} / \mathrm{mg}$ protein/hour) represented as mean $\pm \operatorname{SEM}, n=3{ }^{*} p \leq 0.05$

for a further $8 \mathrm{~h}$. Accumulation of galactosphingolipids was measured by galactose oxidase assay at $16 \mathrm{~h}$ and $24 \mathrm{~h}$ has described. TNF $\alpha$ treatment resulted in an increase in galactosphingolipids in wild-type fibroblasts compared with control samples (without TNF $\alpha$ treatment) (Fig. 4a). Notably, this increase was accentuated by co-treatment of fibroblasts with TNF $\alpha$ and DGJ, used at a concentration which inhibits endogenous $\alpha-G a l$ A activity [19] (Fig. 4a). Moreover, addition of recombinant agalsidase alfa significantly decreased the level of endogenous galactosphingolipids in TNF $\alpha$-treated fibroblasts with respect to control cells (Fig. 4a). To corroborate these results, immunofluorescence microscopy was performed to evaluate the presence of $\mathrm{Gb}_{3}$ (CD77) using an antibody to CD77 (Fig. 4b). In good agreement with the biochemical assay, immunofluorescence staining of fibroblasts exposed to TNFo demonstrated an increase in CD77, which colocalized with the lysosomal membrane marker LAMP1. Additionally, $\mathrm{Gb}_{3}$ signal intensity was increased upon exposure of fibroblasts to TNF $\alpha$ and DGJ (Fig. 4b). Superimposition of CD77/LAMP1 images revealed a significant degree of overlap (Fig. 4b). As anticipated, agalsidase alfa treatment reduced $\mathrm{Gb}_{3}$ accumulation as demonstrated by decreased CD77 fluorescence, without affecting LAMP1 staining (Fig. 4b). Quantification of overlapped pixels of confocal images revealed that TNF $\alpha$ treatment resulted in a 50 fold increase in CD77 staining in fibroblasts, which further increased to 150 fold after $24 \mathrm{~h}$ (Fig. 4c). Cotreatment with DGJ further increased CD77 staining and this was dramatically reduced upon exposure to agalsidase alfa (Fig. 4c). A similar analysis was performed with an antibody to lactosylceramide (CD17). $\alpha$-Gal A catalyzes the hydrolysis of $\mathrm{Gb}_{3}$ to lactosylceramide and $\alpha$-galactose. Lactosylceramide acumulation was decreased upon exposure of fibroblasts to TNF $\alpha$ and DGJ. Agalsidase alfa treatment increased lactosylceramide accumulation as demonstrated by increased CD17 fluorescence, corroborating the CD77 results (Fig. 4c). Collectively, these results show that galactosphingolipids can be precisely measured in cell cultures using this assay and immunocytochemistry is a useful technique to assess lipid storage.

\section{Quantification of galactosphingolipids in leukocytes and human fibroblasts}

Quantification of galactosphingolipids was performed in leukocytes and fibroblasts from $\mathrm{CIH}$ carriers and controls. The individual values of leukocyte galactosphingolipids are presented in Table 1 . The mean value for the control group ( $n=17$ ) was (mean \pm SD) $0.33 \pm 0.30 \mathrm{nmol} / \mathrm{mg}$ protein and in the CIH group $(n=8) 0.42 \pm 0.63 \mathrm{nmol} / \mathrm{mg}$ protein. Galactosphingolipids were also measured in cultured fibroblasts from $\mathrm{CIH}$ patients. After 5 days of quiescence, in all cases galactosphingolipid levels in patient fibroblasts were greater than in equivalent control cell lines, which was significant for patients F1.1, F1.4 and F1.10 (Fig. 5a). Interestingly, in patients F1.3 and F1.4, leukocyte levels were lower than controls, whereas in equivalent fibroblasts the levels were higher. The origin of these differences may reflect distinct GLA expression states of different cells. Ferreira et al., suggest that the GLA 5'UTR polymorphysms are a possible modulators of GLA expression varying among different cell types [24]. Atypical FD variants are often not associated with increased lyso-Gb3 levels, although biopsies of affected organs revealed lamellar inclusion bodies characteristic for FD [25]. Consistent with the increase in galactosphingolipids, immunostaining of fibroblasts from patient F1.4 and F1.10 revealed elevated levels of $\mathrm{Gb}_{3}$, which were further increased after exposure to TNF $\alpha$ (Fig. 5b). Additionally, immunofluorescence revealed that galactolipids were mostly confined to cytosolic and membrane compartments (Fig. 5b). Quantification of CD77/LAMP1 lysosomal co-localization revealed an increase in CD77 staining in fibroblasts from patients F1.4 and F1.10, which was significant for patient F1.10 relative to control values (Fig. 5c).

\section{CDNA analysis}

No sequence changes were discovered after sequencing nested PCR products of the two GLA 


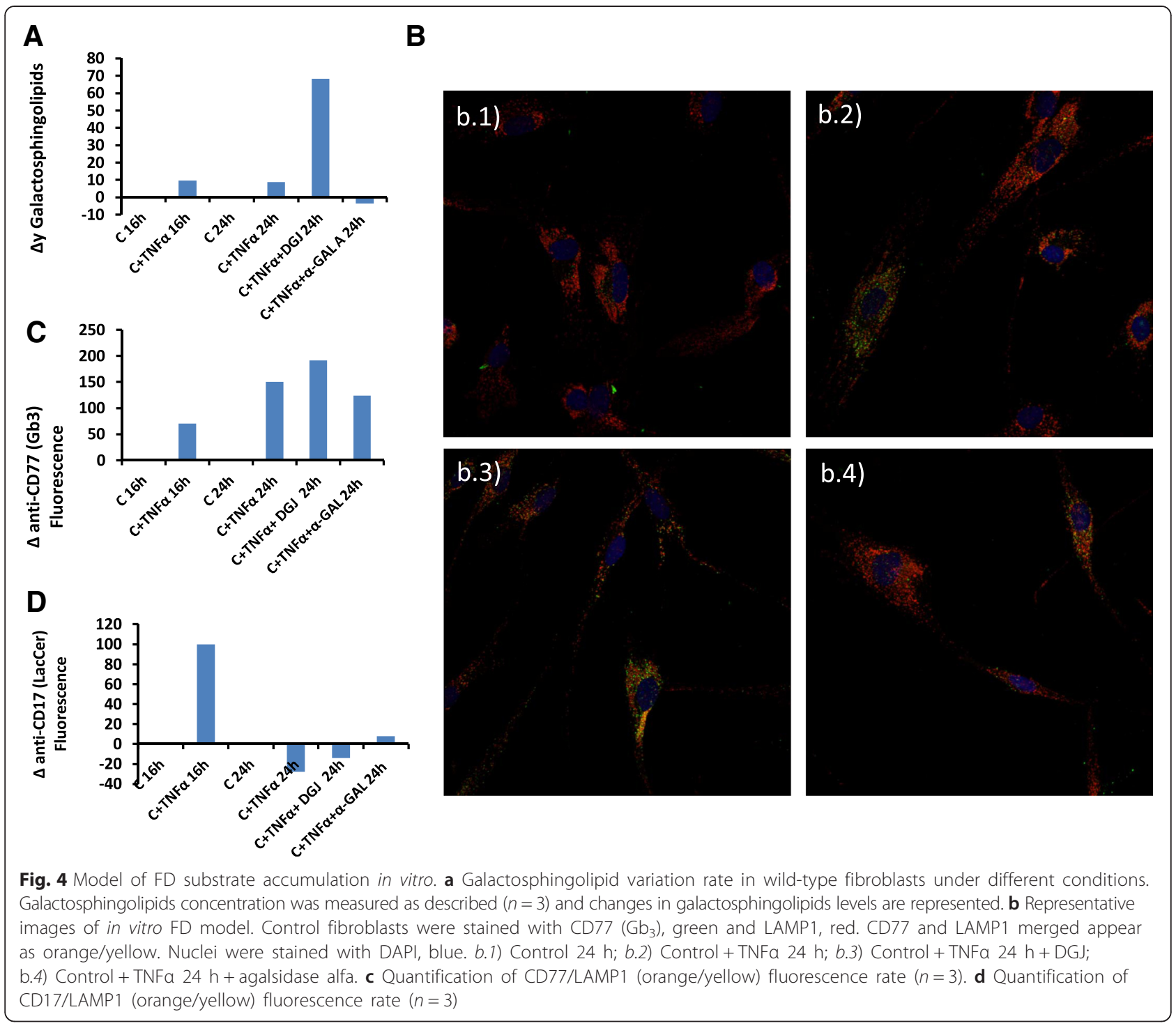

amplicons in comparison with the reference sequence (data not shown).

\section{Small RNA cloning}

Sequencing of the $3^{\prime}$ region of intron 6 insert in all $\mathrm{CIH}$ carriers revealed the presence of one cDNA fragment formed by a 49-bp portion of intron 6 and exon 7 cloned only in patient F1.4. The genomic coordinates of this exon 7 extension are: ChrX(GRCh38): g.101398050-g. $101397803:-1$.

\section{Quantitative PCR of the GLA transcripts}

Relative quantification (RQ) of wild-type (wt) GLA and GLA-M mRNA ( 3 ' region of intron 6 cloned fragment) from all carriers and controls $(n=8 ; 50 \%$ females) was performed by real-time PCR and the GLA/GLA-M expression profiles were compared between control group and carriers. Reduced wt GLA expression was found in all hemizygous carriers and in the heterozygous proband F1.1, and was significant in carriers F1.3, F1.10 and F1.1 (Table 1). The relative expression of GLA-M was increased in carriers F1.2, F1.4 and F1.7, and significantly in patient F1.10 compared with controls (Table 1). The heterozygous group for $\mathrm{CIH}$ presented higher RQ values for GLA wt expression in comparison with the hemizygous group (0.89 vs 0.41 ).

\section{Electrophoretic mobility shift assay (EMSA)}

To investigate whether the $\mathrm{C}>\mathrm{T}$ change in the GLA gene promoter variant c.-10C $>\mathrm{T}$ impacted the binding capacity of possible transcription factors, EMSA was performed with specific primers for each variant. The results demonstrated marked differences in the affinity of nuclear proteins between the two alleles, with allele $\mathrm{C}$ having a greater ability to bind nuclear proteins (Fig. 6a). To confirm this difference, we performed a competitive 


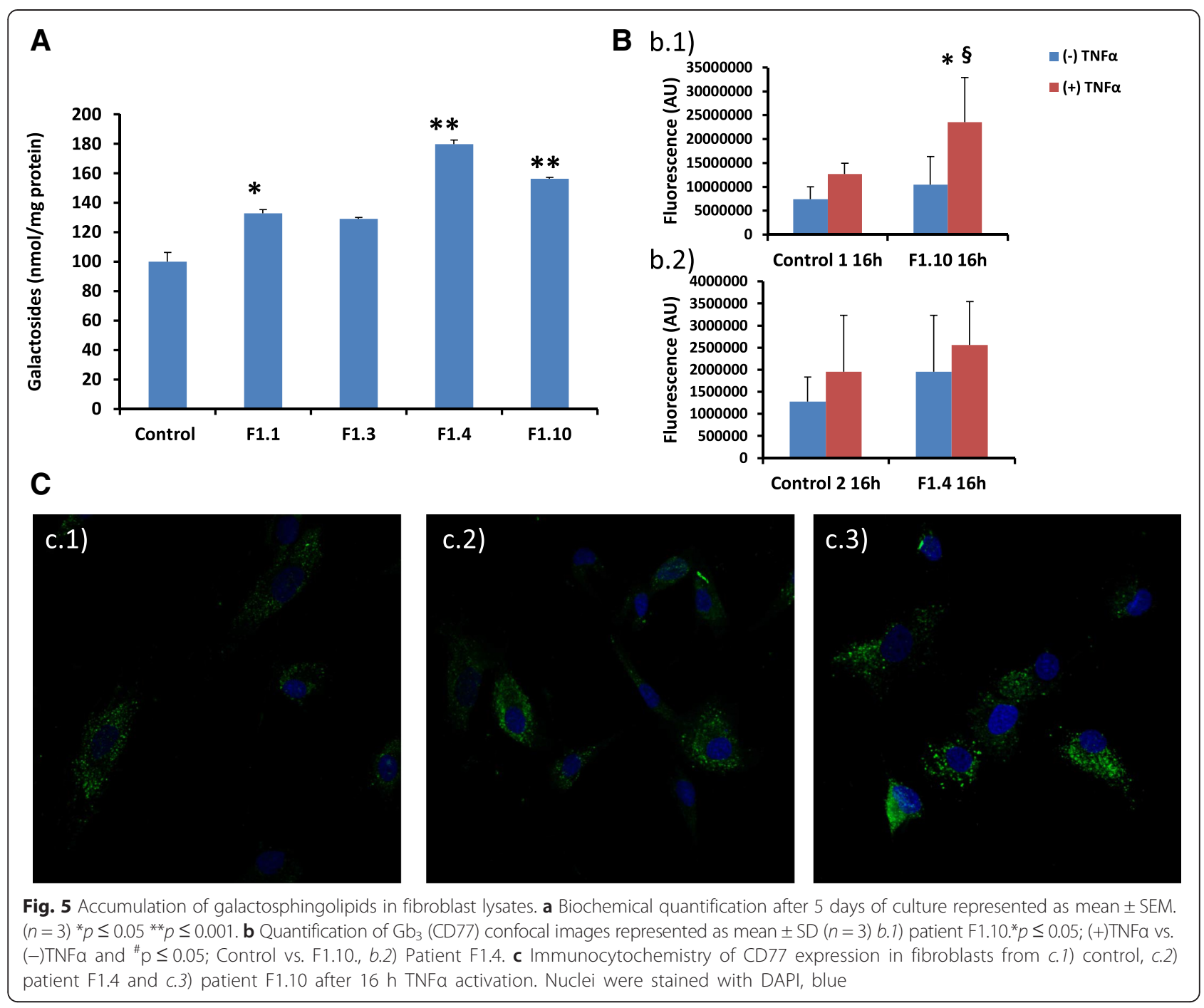

binding EMSA using increasing amounts of an unlabelled oligonucleotide corresponding to the $\mathrm{T}$ allele. The results indicated that the $\mathrm{T}$ allele was more easily displaced from the protein-DNA complex (0.003 vs 0.001) (Fig. 6b). Therefore, the $\mathrm{C}>\mathrm{T}$ substitution resulted in decreased protein binding capacity of the fragment. In an attempt to identify the transcription factors present in the complex, we scanned sequences surrounding the SNP c.-10C $>$ T with MatInspector (Genomatix) [26]. The results of this analysis indicated that the mutation could affect the binding sites for small nuclear RNA (snRNA)-activating protein complex (SNAP-C), doublesex/mab-3 related (DMRT), and X box-binding factors.

\section{Splice-site score (SSS)}

We analysed the variants of the CIH using SSPNN software. Changes in GLA splicing with $\mathrm{CIH}$ were observed only in c.370-81_370-77delCAGCC and c.640-16A > G variants. The c.370-81_370-77delCAGCC variant resulted in the disappearance of a possible acceptor site in IVS2-78, with a SSS of 0.80. The SSS for a normal acceptor site in intron 4 (IVS4-1) was raised from 0.58 to 0.62 with the c. $640-16 \mathrm{~A}>\mathrm{G}$ variant. Although the SSS were minimal, the results indicated that the co-segregation of $\mathrm{CIH}$ variants may cause an abnormal splice pattern.

\section{Discussion}

Detection of mutations in the GLA gene is essential to support clinical diagnosis of FD. Mutations in intronic regions can alter the GLA gene expression pattern in a manner related to different disease phenotypes and clinical manifestations $[4,5]$. Intronic GLA variants often remain unidentified because these regions are not routinely evaluated by gene sequencing; consequently, the prevalence of FD may be underestimated [27, 28]. 


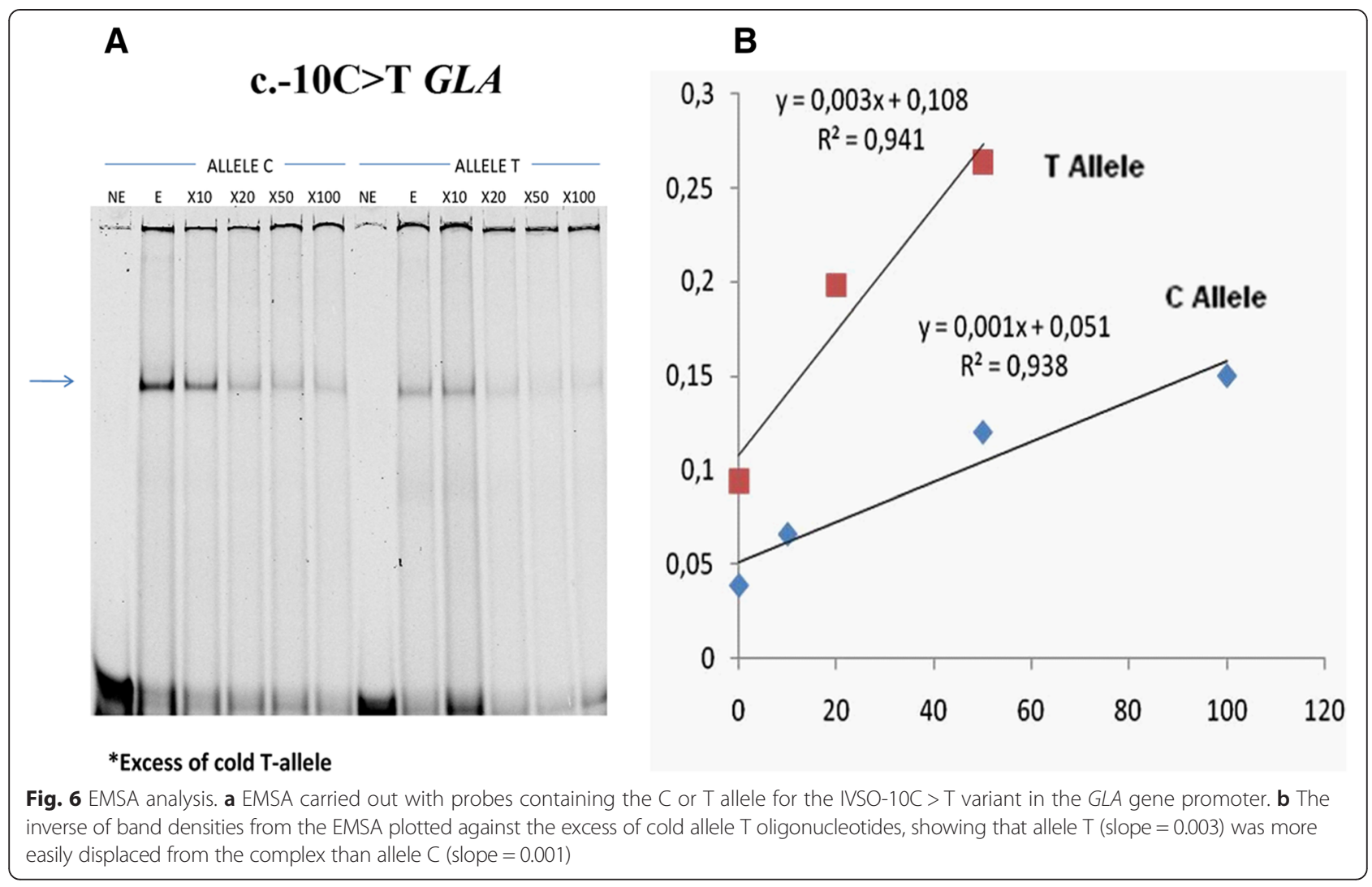

In the present study, we sequenced the entire GLA gene from genomic DNA of the family members and we used MLPA in an attempt to find alterations that could explain the FD-like characteristics observed. We identified a complex haplotype consisting of five intronic variants (c.-10C > T, c.369+990C > A, c.370-81_370-77delCAGCC, c.640-16A > G, c.1000-22C > T). In one study, $12 \%$ of 740 subjects with clinically suspected FD showed polymorphisms in the GLA promoter region; of these, $99 \%$ had simultaneous polymorphisms throughout the gene, and $\mathrm{CIH}$ formed by four of five variants observed in our study occurred in $9 \%$ of these cases [11]. In a second study, Ferri and colleagues [13] identified five GLA haplotypes in non-coding regions in 67 female probands with FD manifestations. The most frequent of these was the $\mathrm{CIH}$ formed by four variants (13.4\%). Previous reports have found c.-10C $>$ T, c.370-81_370-77delCAGCC, c.640$16 \mathrm{~A}>\mathrm{G}$ and c.1000-22C $>\mathrm{T}$ variants to be associated with different clinical manifestations including mild renal, neurological [10] and cardiac disorders [12]. It is important to know that depending on the sequencing design, these haplotypes might be the same type. We found FD-like symptoms (renal, cardiac and neurological involvement) associated with the family in our study (Table 1). In accordance with our results Apeland et al., described two unrelated families, one of them carrier of c. $640-16 \mathrm{~A}>\mathrm{G}$ and c.1000-22C $>\mathrm{T}$ intronic variants, presenting a cardiomyopathy mimicking FD with normal enzymatic activity values and renal and cardiac deposits without accumulation of glycolipids in urine or plasma. In two patients, a 100-fold increase in Gb3 was observed in cardiac biopsies. Exon sequencing failed to detect heterozygosity in potential candidate genes [29].

We examined the c.-10C $>\mathrm{T}$ variant located in the GLA gene promoter region, which may be codominantly associated with a relatively decreased GLA expression at the level of transcription and/or translation [30]. By EMSA, we found that the $\mathrm{T}$ allele reduced the affinity of the nuclear protein binding site. A computer analysis using MatInspector showed that this region is a possible binding site for three families of transcription factors: SNAP-C, X box-binding factors (XBBF) and DMRT. SNAP-C binds to Oct- 1 and TATA binding proteins (TBP), which are activators of snRNA and RNA polymerases, respectively [31]. X box-Protein 1 (XBP1) becomes initiated during the endoplasmic reticulum (ER) stress response [32]. In humans, the DMRT gene family encodes transcription factors that are related to the Drosophila double sex proteins [33]. Unfortunately, no tested antibodies are currently available to perform a supershift assay.

The c.-10 C > T variant is situated in a $\mathrm{CpG}$ island region (http://www.urogene.org/methprimer/). DNA methylation 
is a well-recognized epigenetic modifier in the control of gene expression. This reversible DNA modification takes place almost exclusively at cytosine residues that are associated with guanosine in CpG doublets, and mediates control of transcription through chromatin remodelling. This modification is widely implicated in various biological processes including $\mathrm{X}$-inactivation, the regulation of tissue- and development-specific gene expression, foreign DNA inactivation and genomic imprinting [34]. FD symptoms exhibited by females carrying the $\mathrm{T}$ allele could partially depend on the methylation state of the $\mathrm{C}$ allele. Indeed, Bono and co-workers [11] reported a relationship between FD symptoms and polymorphisms in the promoter region. Future studies on the methylation states of the promoter region may provide more clues on these epigenetic effects in relation to phenotype.

We found low levels of wild-type transcript in some patients in agreement with previous reports [28, 35]. GLA-M transcript levels ( $3^{\prime}$ region of the intron 6 cloned fragment) were also altered with respect to their controls in most cases. The index case of this family (F1.1), a female heterozygous for $\mathrm{CIH}$, presented significantly lower levels of wild-type transcript, whereas GLA$M$ expression was slightly reduced but not significantly different to control. Although she presented a cardiac phenotype, her leukocyte and plasma enzyme activities were not decreased. Higher residual activity is often found in atypical male patients who do not show the classic phenotype and have later onset of symptoms [36, 37], including cardiac [35] and renal variants [38]. It is possible that GLA expression in other tissues may be different. The ratio of the alternatively spliced transcript produced by another intronic variant, IVS4 + 919G > A mutation, to total $\alpha-G a l$ A mRNA, is higher in human muscle and lung tissues [27]. In the case of this studied family, the $\mathrm{CIH}$ only produced an altered GLA expression profile, presumably resulting in a late-onset FD-like phenotype. The differences observed in the qPCR assay may coincide with the SSS data variations for c.370-81_370-77delCAGCC and c.640-16A $>$ G variants, the EMSA assay results for c.$10 \mathrm{C}>\mathrm{T}$ and also with the cDNA cloned fragment formed by a 49-bp segment of $3^{\prime}$ intron 6 and exon 7 in patient F1.4. However, PCR and sequencing did not reveal any products of splicing variants due to c.370-81_370-77delCAGCC or c.640-16A > G. It is possible that these transcripts are degraded by nonsense-mediated mRNA decay. In accord with the EMSA results, the expression levels of heterozygous $\mathrm{CIH}$ patients were approximately $50 \%$ higher than in hemizygous carriers. Enzymatic activity was measured in plasma, lysed leukocytes and fibroblasts from $\mathrm{CIH}$ carriers and normal healthy controls. The mean value of lysed leukocyte activity in the $\mathrm{CIH}$ group was significantly lower $(\sim 20 \%)$ but there was no significant difference between the plasma and fibroblast activity in control and $\mathrm{CIH}$ group. The expression is reduced in leukocytes reducing the enzyme activity but no the enzyme activity in other tissues like plasma supporting previous studies [30]. This effect may contribute to the glycolipid alteration and therefore may develop the clinical findings.

The levels of storage products in urine and plasma are elevated in most, but not all, FD patients. The demonstration of increased storage product levels is very useful in making a diagnosis in many cases and also for treatment monitoring. The predominant storage product in $\mathrm{FD}$ is $\mathrm{Gb}_{3}$, but other storage products such as $\mathrm{Ga}_{2}$ or lyso- $\mathrm{Gb}_{3}$ may also accumulate. Consequently, significant differences in the $\mathrm{Gb}_{3}$ and $\mathrm{Ga}_{2}$ isoform profiles in urinary sediment were found amongst young, adult and atypical hemizygotes and heterozygotes using a combination of MALDI-TOF MS and tandem MS [39]. Additionally, increased sphingolipid storage in skin fibroblasts from patients has been described previously [40]. Therefore, we used an enzymatic fluorometric technique to quantify all galactosphingolipids in samples obtained from controls and $\mathrm{CIH}$ carriers in lysed leukocytes and skin fibroblasts. Galactose is a component of the headgroup of many glycolipids. Galactose oxidase specifically oxidizes the C-6 hydroxymethyl group of free galactose as well as all galactosyl derivatives, such as $\mathrm{Gb}_{3}$, lyso- $\mathrm{Gb}_{3}$ and $\mathrm{Ga}_{2}$, carrying a galactose residue in the terminal position. Bile acids, for example sodium taurocholate, do not alter the kinetics of galactose oxidase [41]. The enzymatic method to detect urinary $\mathrm{Gb}_{3}$, showed a good recovery and comparability with a previously validated HPLC method [42]. Importantly, we validated this assay using a synthetic model of lysosomal storage in fibroblasts activated with TNF $\alpha$ and corroborated these findings with confocal microscopy quantification of CD77 (Gb3)/CD17(Lactosylceramide)/ LAMP1. Confocal microscopy revealed that galactolipids were mostly confined to cytosolic and membrane compartments (Fig. 5b) in concordance with several studies that demonstrated that Gb3 in FD is not only present in lysosomes, but rather widely distributed in other cellular structures [43]. In vitro studies in skin fibroblasts showed that $\mathrm{CIH}$ carriers accumulated galactosphingolipids significantly after 5 days culture, in the range between 30 and $80 \%$ in comparison with control samples. Fibroblasts from a male patient (F1.4) with a renal phenotype and glycolipid deposits demonstrated by renal biopsy, accumulated approximately $50 \%$ more substrate compared with the F1.1 patient, a heterozygous female with a cardiac phenotype. In concordance with our results is important to remark that Namdar et al. demonstrated that vasculopathy in FD is directly caused by intracellular Gb3 accumulation while deficiency of GLA alone does not cause any deregulation of key vasoactive mediators [44]. 
Most of the carriers had high in vitro residual enzyme activity in plasma, leukocytes and cultured fibroblasts; however, $\mathrm{CIH}$ carriers had significant galactosphingolipid accumulation in fibroblasts in comparison with controls. Presumably, because the enzyme structure is not altered, only the GLA structural regulatory mechanism was affected by inheritance of the $\mathrm{CIH}$, leading to GLA activationdependent accumulation of substrates, influenced perhaps by environmental factors such as the proinflammatory state of the patient.

\section{Conclusions}

$\mathrm{CIH}$ carriers showed a wide variation in residual enzymatic activities in leukocytes, plasma, and fibroblasts, but generally activity was normal. In contrast, galactosphingolipid accumulation was in the main significantly greater in fibroblasts compared with controls. Position -10 in the GLA promoter is a putative nuclear protein binding site situated in the $\mathrm{CpG}$ island region, acting as a gene regulatory zone. The inheritance of the co-segregated $\mathrm{CIH}$ variants alters the GLA expression pattern, producing a tissue glycolipid storage disorder.

The genetic analysis of the entire GLA gene sequence and MLPA, the study of GLA expression and glycolipid quantification in relation to FD clinical manifestations can be extremely helpful as tools for FD-related diagnosis.

Further studies are needed to elucidate how the inheritance of complex intronic haplotypes are implicated in the GLA regulatory mechanisms and therefore, the glycolipid metabolism alteration.

\section{Additional file}

Additional file 1: Table S- Sequences of primers and probes. (DOCX $21 \mathrm{~kb}$ )

\begin{abstract}
Abbreviations
GLA: Alfa galactosidase gene; FD: Fabry disease; Gb 3 : Globotriaosylcermide; Lyso-Gb 3 : Globotriaosylsphingosine; Ga2: Galabiosylceramide; a-Gal A: a-galactosidase A; ClH: Complex intronic haplotype; TNFa: Tumor necrosis factor alpha; LAMP1: Lysosomal-associated membrane protein 1; DGJ: 1-deoxygalactonojirimycin hydrochloride; MU: Methylumbelliferyl; PCR: Polymerase chain reaction; RT-PCR: Reverse transcription polymerase chain reaction; MLPA: Multiplex ligand probe amplification; FBS: Fetal bovine serum; DMEM: Dulbecco's modified Eagle's medium; qPCR: Quantitative real-time PCR; EMSA: Electrophoretic mobility shift assay; SSS: Splice-site score; MRI: Magnetic resonance image; LV: Left ventricle; LVEF: Left ventricular ejection fraction; MI: Mitral insufficiency; Al: Aortic insufficiency; QST: Quantitative sensory test; RQ: Relative quantification; Wt: Wild type; SNP: Single nucleotide polymorphism; snRNA: Small nuclear RNA; SNAP-C: Small nuclear RNA activating protein complex; XBBF: X box-binding factors; DMRT: Doublesex/mab-3 related; TBP: TATA binding proteins.
\end{abstract}

\section{Competing interests}

The authors declare that they have no competing interests.

\section{Authors' contributions}

JGA, JCRR and MP conceived and designed the experiments. JGA, JJC, PI and JPL performed the experiments. JGA carried out statistical analysis. LP carried out the renal biopsy analyzes. JLC, JCR and PG carried out the clinical evaluation. JLC, JCR, JCRR, MP and PG contributed reagents/materials/analysis tools. JGA drafted the manuscript. JGA, JJC, JCRR, MP and PG carried out the interpretation of data. JGA, MP and PG participated in the design and coordination of the study. All authors read and approved the final manuscript.

\section{Acknowledgements}

The authors gratefully thank Cesar Vallejo for technical support; Dr. Erika Fernandez-Vizarra for critical revision of the manuscript and Dr. Gracia Mendoza for immunofluorescence support. This study was supported by grant FIS (PI 09/02556) and by the Centro de Investigación Biomédica en Red de Enfermedades Raras (CIBERER), an initiative of the ISCIII.

\section{Author details}

${ }^{1}$ Centro de Investigación Biomédica en Red de Enfermedades Raras (CIBERER), Zaragoza, Spain. ${ }^{2}$ Translational Research Unit, Instituto de Investigación Sanitaria Aragón (IIS Aragón), Miguel Servet University Hospital, Zaragoza, Spain. Instituto de Investigación Sanitaria Aragón (IIS Aragón), Zaragoza, Spain. ${ }^{4}$ Biochemistry and Molecular and Cellular Biology Department, Universidad de Zaragoza, Zaragoza, Spain. ${ }^{5}$ Molecular Biology Department, Cantabria University and IFIMAV, Santander, Spain. ${ }^{6}$ Anatomic Pathology Department, Miguel Servet University Hospital, Zaragoza, Spain. ${ }^{7}$ Neurology Department, Miguel Servet University Hospital, Zaragoza, Spain.

Received: 9 April 2015 Accepted: 25 August 2015

Published online: 03 September 2015

\section{References}

1. Desnick R, loannou Y, Eng C. Fabry disease: a-galactosidase A deficiency. In: Scriver C, editor. Metabolic and molecular bases of inherited disease. New York: McGraw-Hill; 2001. p. 3733-74.

2. Mehta A, Ricci R, Widmer U, Dehout F, Garcia de Lorenzo A, Kampmann C, et al. Fabry disease defined: baseline clinical manifestations of 366 patients in the Fabry Outcome Survey. Eur J Clin Invest. 2004;34(3):236-42.

3. Lyon MF. Gene action in the X-chromosome of the mouse (Mus musculus L.) Nature. 1961;190:372-3.

4. Spada M, Pagliardini S, Yasuda M, Tukel T, Thiagarajan G, Sakuraba H, et al. High incidence of later-onset fabry disease revealed by newborn screening. Am J Hum Genet. 2006;79(1):31-40.

5. Hwu WL, Chien YH, Lee NC, Chiang SC, Dobrovolny R, Huang AC, et al. Newborn screening for Fabry disease in Taiwan reveals a high incidence of the later-onset GLA mutation c.936+919G>A (IVS4+919G>A). Hum Mutat. 2009;30(10):1397-405.

6. Desnick RJ, Brady R, Barranger J, Collins AJ, Germain DP, Goldman M, et al. Fabry disease, an under-recognized multisystemic disorder: expert recommendations for diagnosis, management, and enzyme replacement therapy. Ann Intern Med. 2003;138(4):338-46.

7. Eng CM, Germain DP, Banikazemi M, Warnock DG, Wanner C, Hopkin RJ, et al. Fabry disease: guidelines for the evaluation and management of multi-organ system involvement. Genet Med. 2006;8(9):539-48.

8. Stenson PD, Ball EV, Mort M, Phillips AD, Shiel JA, Thomas NS, et al. Human Gene Mutation Database (HGMD): 2003 update. Hum Mutat. 2003;21(6):577-81.

9. Lai LW, Whitehair O, Wu MJ, O'Meara M, Lien YH. Analysis of splice-site mutations of the alpha-galactosidase A gene in Fabry disease. Clin Genet. 2003;63(6):476-82.

10. Tanislav C, Kaps M, Rolfs A, Bottcher T, Lackner K, Paschke E, et al. Frequency of Fabry disease in patients with small-fibre neuropathy of unknown aetiology: a pilot study. Eur I Neurol. 2011;18(4):631-6.

11. Bono C, Nuzzo D, Albeggiani G, Zizzo C, Francofonte D, lemolo F, et al. Genetic screening of Fabry patients with EcoTILLING and HRM technology. BMC Res Notes. 2011;4:323.

12. Pisani A, Imbriaco M, Zizzo C, Albeggiani G, Colomba P, Alessandro R, et al. A classical phenotype of Anderson-Fabry disease in a female patient with intronic mutations of the GLA gene: a case report. BMC Cardiovasc Disord. 2012;12:39.

13. Ferri L, Guido C, la Marca G, Malvagia S, Cavicchi C, Fiumara A, et al. Fabry disease: polymorphic haplotypes and a novel missense mutation in the GLA gene. Clin Genet. 2012;81(3):224-33.

14. Tuttolomondo A, Duro G, Pecoraro R, Simonetta I, Miceli S, Colomba P, et al. A family with various symptomatology suggestive of Anderson-Fabry disease and a genetic polymorphism of alpha galactosidase A gene. Clin Biochem. 2015;48(1-2):55-62. 
15. Oliveira JP, Ferreira S, Barcelo J, Gaspar P, Carvalho F, Sa Miranda MC, et al. Effect of single-nucleotide polymorphisms of the 5 ' untranslated region of the human alpha-galactosidase gene on enzyme activity, and their frequencies in Portuguese caucasians. J Inherit Metab Dis. 2008;31 Suppl 2:S247-53.

16. Davies JP, Winchester BG, Malcolm S. Sequence variations in the first exon of alpha-galactosidase A. J Med Genet. 1993;30(8):658-63.

17. Bekri S, Enica A, Ghafari T, Plaza G, Champenois I, Choukroun G, et al. Fabry disease in patients with end-stage renal failure: the potential benefits of screening. Nephron Clin Pract. 2005;101(1):c33-8.

18. Mayes JS, Scheerer JB, Sifers RN, Donaldson ML. Differential assay for lysosomal alpha-galactosidases in human tissues and its application to Fabry's disease. Clin Chim Acta. 1981;112(2):247-51.

19. Hsu J, Serrano D, Bhowmick T, Kumar K, Shen Y, Kuo YC, et al. Enhanced endothelial delivery and biochemical effects of alphagalactosidase by ICAM-1-targeted nanocarriers for Fabry disease. J Control Release. 149. Netherlands: 2010 Elsevier B.V; 2011. p. 323-31.

20. Keslová-Veselíková J, Hůlková H, Dobrovolný R, Asfaw B, Poupetová H, Berná $L$, et al. Replacement of alpha-galactosidase $A$ in Fabry disease: effect on fibroblast cultures compared with biopsied tissues of treated patients. Virchows Arch. 2008:452(6):651-65.

21. Pfaffl M. Relative quantification. In: Dorak T, editor. Real-time PCR. La Jolla, CA: International University Line; 2006. p. 63-82.

22. Riancho JA, Vazquez L, Garcia-Perez MA, Sainz J, Olmos JM, Hernandez JL, et al. Association of ACACB polymorphisms with obesity and diabetes. Mol Genet Metab. 2011;104(4):670-6.

23. Rolke R, Baron R, Maier C, Tolle TR, Treede RD, Beyer A, et al. Quantitative sensory testing in the German Research Network on Neuropathic Pain (DFNS) standardized protocol and reference values. Pain. 2006;123(3):231-43.

24. Ferreira, S., C. Reguenga, and J.P. Oliveira, The Modulatory Effects of the Polymorphisms in GLA 5'-Untranslated Region Upon Gene Expression Are Cell-Type Specific. JIMD Rep, 2015.

25. Mitobe S, Togawa T, Tsukimura T, Kodama T, Tanaka T, Doi K, et al. Mutant alpha-galactosidase A with M296I does not cause elevation of the plasma globotriaosylsphingosine level. Mol Genet Metab. 2012;107(3):623-6.

26. Quandt K, Frech K, Karas H, Wingender E, Werner T. MatInd and MatInspector: new fast and versatile tools for detection of consensus matches in nucleotide sequence data. Nucleic Acids Res. 1995:23(23):4878-84.

27. Ishii S, Nakao S, Minamikawa-Tachino R, Desnick RJ, Fan JQ. Alternative splicing in the alpha-galactosidase A gene: increased exon inclusion results in the Fabry cardiac phenotype. Am J Hum Genet. 2002;70(4):994-1002.

28. Filoni C, Caciotti A, Carraresi L, Donati MA, Mignani R, Parini R, et al. Unbalanced GLA mRNAs ratio quantified by real-time PCR in Fabry patients' fibroblasts results in Fabry disease. Eur J Hum Genet. 2008;16(11):1311-7.

29. Apelland T, Gude E, Strøm EH, Gullestad L, Eiklid KL, Månsson JE, et al. Familial globotriaosylceramide-associated cardiomyopathy mimicking Fabry disease. Heart. 2014;100(22):1793-8.

30. Oliveira JP, Ferreira S, Reguenga C, Carvalho F, Mansson JE. The g.1170C>T polymorphism of the $5^{\prime}$ untranslated region of the human alphagalactosidase gene is associated with decreased enzyme expressionevidence from a family study. J Inherit Metab Dis. 2008;31 Suppl 2:S405-13.

31. Sadowski CL, Henry RW, Kobayashi R, Hernandez N. The SNAP45 subunit of the small nuclear RNA (snRNA) activating protein complex is required for RNA polymerase II and III snRNA gene transcription and interacts with the TATA box binding protein. Proc Natl Acad Sci U S A. 1996;93(9):4289-93.

32. Iwakoshi NN, Lee AH, Glimcher LH. The X-box binding protein-1 transcription factor is required for plasma cell differentiation and the unfolded protein response. Immunol Rev. 2003;194:29-38.

33. Hong CS, Park BY, Saint-Jeannet JP. The function of Dmrt genes in vertebrate development: it is not just about sex. Dev Biol. 2007;310(1):1-9.

34. Robertson KD, Wolffe AP. DNA methylation in health and disease. Nat Rev Genet. 2000;1(1):11-9.

35. Nakao S, Takenaka T, Maeda M, Kodama C, Tanaka A, Tahara M, et al. An atypical variant of Fabry's disease in men with left ventricular hypertrophy. N Engl J Med. 1995;333(5):288-93.

36. Ishii S, Chang HH, Kawasaki K, Yasuda K, Wu HL, Garman SC, et al. Mutant alpha-galactosidase A enzymes identified in Fabry disease patients with residual enzyme activity: biochemical characterization and restoration of normal intracellular processing by 1-deoxygalactonojirimycin. Biochem J. 406. England2007. p. 285-95.
37. Winchester B, Young E. Biochemical and genetic diagnosis of Fabry disease. In: Mehta A, Beck M, Sunder-Plassmann G, editors. Fabry disease: perspectives from 5 years ofFOS. Oxford: Pharmagenesis; 2006. p. 169-81.

38. Nakao S, Kodama C, Takenaka T, Tanaka A, Yasumoto Y, Yoshida A, et al. Fabry disease: detection of undiagnosed hemodialysis patients and identification of a "renal variant" phenotype. Kidney Int. 64. United States2003. p. 801-7.

39. Touboul D, Roy S, Germain DP, Baillet A, Brion F, Prognon P, et al. Fast fingerprinting by MALDI-TOF mass spectrometry of urinary sediment glycosphingolipids in Fabry disease. Anal Bioanal Chem. 2005;382(5):1209-16.

40. Kanekura T, Fukushige T, Kanda A, Tsuyama S, Murata F, Sakuraba H, et al. Immunoelectron-microscopic detection of globotriaosylceramide accumulated in the skin of patients with Fabry disease. Br J Dermatol. 2005;153(3):544-8.

41. Fortelius M, Mattjus P. Galactose oxidase action on galactose containing glycolipids-a fluorescence method. Chem Phys Lipids. 2006;142(1-2):103-10.

42. Rozenfeld PA, De Francesco NP, Borrajo GJ, Ceci R, Fossati CA. An easy and sensitive method for determination of globotriaosylceramide (Gb3) from urinary sediment: utility for Fabry disease diagnosis and treatment monitoring. Clin Chim Acta. 403. Netherlands2009. p. 194-7.

43. Askari H, Kaneski CR, Semino-Mora C, Desai P, Ang A, Kleiner DE, et al. Cellular and tissue localization of globotriaosylceramide in Fabry disease. Virchows Arch. 2007:451(4):823-34.

44. Namdar M, Gebhard C, Studiger R, Shi Y, Mocharla P, Schmied C, et al. Globotriaosylsphingosine accumulation and not alpha-galactosidase-A deficiency causes endothelial dysfunction in Fabry disease. PLoS One. 7. United States2012. p. e36373.

\section{Submit your next manuscript to BioMed Central and take full advantage of:}

- Convenient online submission

- Thorough peer review

- No space constraints or color figure charges

- Immediate publication on acceptance

- Inclusion in PubMed, CAS, Scopus and Google Scholar

- Research which is freely available for redistribution 